\title{
Pre-Scaling Up of Hay-Box Brooding Technology to Selected Districts of Arsi and West Arsi Zones
}

\author{
Aman Nebo $^{1} \quad$ Abayineh Awgichew ${ }^{2}$ \\ Oromiya Agricultural Research Institute (IQQO), \\ Asella Agricultural Engineering Research Center. P.O.Box 06 Asella Ethiopia
}

\begin{abstract}
The research was carried out in three purposively selected districts namely Digalu-Tijo from Arsi, Asasa and Adaba from west Arsi zones with objectives of transferring and popularizing hay-box chick brooding technology to farmers, and enhancing linkage between research, extension and farmers in the study areas. From these districts six peasant associations were purposively selected based on their accessibility from list of peasant associations. Then, a total of six groups one at each peasant associations which have an average of twenty members of farmers composed of male, female and youth were organized to undertake demonstration and popularization of hay-box chick brooder. A total of 92 farmers of which $54.36 \%$ were female farmers have attended the training. From each farmers research extension group one trial farmer was selected and a brooder having capacity of twenty chicks was given with twenty chicks bought from commercial firms in Bishoftu each including feeds that can serve for three months. Out of the total 121 chicks distributed to farmers only five died and around $96 \%$ grown up to layer stage which is six months of age. Mini-field-days where organized to share experiences and knowledge and all the farmers who attended the demonstration understood the double advantages of this technology reducing number of chicks died because of predator and save time that the broody hens spent to rear chicks.
\end{abstract}

Keywords: Hay Box Chick Brooder, Demonstration, Popularization, Training

DOI: $10.7176 / \mathrm{JBAH} / 11-2-05$

Publication date: January $31^{\text {st }} 2021$

\section{INTRODUCTION}

Poultry production is an important economic activity in Ethiopia. Beside its social and cultural benefits it plays a significant role in family nutrition. The country has about $60 \%$ of the total chicken population of East Africa (Mekonnen G 2007). Rural small holder farmers keep more than $95 \%$ of this population and practice scavenging management conditions. The remaining insignificant proportion which is $5 \%$ comes from the commercial sector.

According to Tadelle and Ogle (2001), more than ninety five percent of the poultry in rural Ethiopia, baby chicks are raised by broody hen, since it is difficult to adopt artificial brooders by household poultry keeprs. About $60 \%$ of the chicks hatched in the rural area of Ethiopia die during the first eight weeks of their life. In rural part of the country, a broody hen raises on an average of 2.8 chicks and it took her around 81 days to do so after hatching. Sometimes the broody hen may raise zero chicks depending on the maternal instinct of the mother hen and prevalence of predators in the vicinity. The premature chicks may die due to birds of prey, pets and some wild animals. on the other hand if the hatched chicks are raised by artificial brooder, the broody hen will back to laying of eggs with short period of time and its productivity will increase and moreover, the chicks will be more safer than natural brooding (The Ethiopian Sub-Sector Review 4, 1884; Hoyle, 1992 and CSA, 1985-1996).

Asella agricultural mechanization research center attempted to adapt Hay-box brooding technology, developed at Jimma College of Agriculture. From the result obtained during the adaptation of this technology it seems to hold promise in bridging this gap to some extent. Therefor; this study intends to demonstrate and popularize this technology through establishment of farmer's research and extension groups (FREG) in selected GTP-II districts of Arsi and West Arsi zones with specific objectives of demonstrating and popularizing of haybox chick brooding technology to farmers in the selected AGP-II districts of Arsi and West Arsi zones

\section{MATERIAL AND METHODS \\ Materials}

Materials needed for the production of hay-box chick brooding technology such as timber, mesh wire of different size, nails, sack and other necessary materials purchased from market. Then production of hay-box chick brooders technology was constructed in the wood work workshop. The other materials were day-old chicks and poultry feeds and these were obtained from poultry farms and poultry feed processing factories.

\section{Methods}

To transfer and popularize the hay-box chick brooding technology; three districts namely Digelu Tijo from Arsi zone and Gedeb Asasa and Adaba from west Arsi zone were purposively selected from two zones based on their potential and accessibility. From these districts six peasant associations were purposively selected from list of peasant association using similar procedure and criteria. In collaboration with districts' agency of livestock and 
fishery resources development experts and respective peasant associations development agents, discussions were held to select willing farmers who were interested on poultry production and also had some experiences in traditional way of poultry production was selected. Proxy to each other of the households was also considered in order to facilitate group working among group members. Then, six groups each having twenty members of farmers comprised of male, female and youth were organized in the selected peasant associations to undertake demonstration and popularization of hay-box chicken brooding technology. As from the nature of the technology and the enterprise itself, most rural females were working at home and near to poultry productions, and more attention was given to females in selection process of farmers' research extension group.

\section{Stakeholder analysis}

In enhancing hay-box chick brooding technology dissemination, improving poultry production and productivity, the research center was closely working and made frequent consultation with its respective stakeholders. Prescaling up activity should be done by different actors in partnership and collaborative approach. So, stakeholder analysis is highly important for institutional arrangement before embarking on the pre-scaling up activity. Thus, stakeholder analysis was undertaken to identify potential stakeholders. Points such as: Who are the stakeholders? How much they are closer to the project? What are their roles, duties and responsibilities in implementing the activity? And finally the roles, duties and responsibilities of each actor were clearly stated in implementing the activity. Accordingly, 5 responsible and collaborative participant stakeholders/actors were identified. Namely, poultry farm which was Alem Poultry Farm PLC, Asella Agricultural Engineering Research Center, Arsi and West Arsi Zones Livestock Agencies, two micro-enterprises from each districts; Digalu and Tijo, Gedeb Asasa and Adaba Districts Live Stock Agencies. Besides, stakeholders' forum was organized for consultation meeting; stakeholder platforms were established at zone and

District levels; Memorandum of Understanding (MoU) was signed.

\section{Communication methods used}

Appropriate extension approaches (project and participatory) and all extension teaching methods (individual, group and mass contact methods) were employed alone or in a judicious combination according to the situations during the implementation of the pre-scaling up activity.

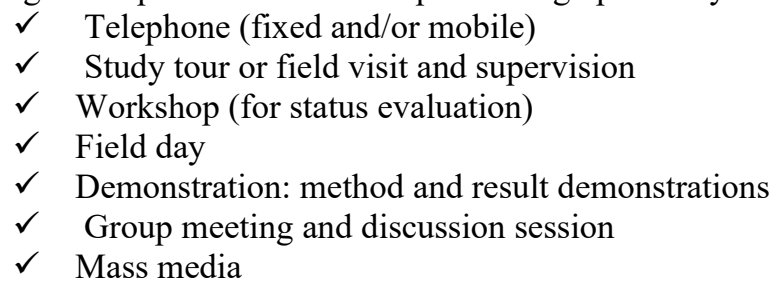

Table 1

Stakeholder roles and responsibilities in implementing the activity

\begin{tabular}{|c|c|}
\hline Stakeholders & Roles and responsibilities \\
\hline Asella Agricultural & * Coordination and facilitation, \\
\hline Engineering research & * Provision of hay-box technology \\
\hline center & * Provision of training \\
\hline & * Technical backstopping \\
\hline & * Organize field days and Supervision and joint monitoring and evaluation \\
\hline Poultry farms & * production of chicken and poultry feeds \\
\hline Micro-enterprises & * production of hay-box chick brooder \\
\hline District and Zone level & * Assist in site and participant farmers' selection \\
\hline Livestock agencies & * Follow up day to day activities \\
\hline & * Assist in providing training \\
\hline & * Facilitate chicken and hay-box distribution \\
\hline & * Jointly organize and participate on field days \\
\hline Farmers & * Allocate land and perform required practices \\
\hline producers) & * Actively participate in the training \\
\hline & * Share skills and experiences to neighbor farmers \\
\hline
\end{tabular}

\section{RESULTS AND DISCUSSIONS}

Training

The training given was mainly classified into two parts. First part was on importance and how to use hay-box chicken brooding technology. This training was given by the researchers from Asella agricultural engineering 
research center. The training given includes raw materials selection in hay-box brooding technology production, importance of the technology compared to traditional hens brooding (advantages over traditional way of rearing chicken hay-box brooder), attention to be given while using the technology. The second part of the training includes the biological parts and generally it was on importance of poultry production, major determinant factors and cares to be taken while dealing with poultry, disease management, how to feed poultry and etc. this part of the training was given by the poultry experts from the respective districts. A total of 108 participants of which about $48 \%$ female and about 52\% males have attended the training successfully. The training mainly focuses on promotion of technology and awareness creation among farmers and participant stakeholders. After training, all the six FREGs were provided with a brooder having capacity of twenty chicks and twenty chicks along their feeds which could serve for three months. Out of the total 121 chicks distributed to farmers around 96\% (116) chicks have survived and grown to layers stage which is six months of age.

Table 1: Training given for farmers, development agents and districts experts

\begin{tabular}{|l|l|l|l|l|}
\hline Districts & Participants & Male & Female & Total \\
\hline Digelu Tijo & Farmers & 15 & 17 & 32 \\
& Experts & 3 & - & 3 \\
& Das & 2 & - & 2 \\
\hline Gedeb Asasa & Farmers & 15 & 15 & 30 \\
& Experts & 3 & - & 3 \\
& Das & 1 & 1 & 2 \\
\hline Adaba & Farmers & 12 & 18 & 30 \\
& Experts & 4 & - & 4 \\
& Das & 1 & 1 & 2 \\
\hline
\end{tabular}

\section{Farmers' perception towards technology}

All participants in the technology demonstration process prefer this technology over the traditional way of rearing their poultry and show their interest to have this technology for their future poultry production.

\section{CONCLUSION AND RECOMMENDATIONS}

This research was conducted in three purposively selected AGP-II districts of Arsi and west Arsi zones namely Digelu Tijo, Gedeb Asasa and Adaba because of their appropriateness for the technology being demonstrated. To undertake demonstration of this technology two peasant association from each districts were selected and six FREG of which $56(57.1 \%)$ were female and about $47(42.9 \%)$ of them were male were established. To facilitate demonstration process both process and result demonstration methods were used. All FREG members and other participants prefer hay-box chick brooding technology for their future poultry production purpose.

Therefore, further promotion and popularization and wider multiplication and dissemination of the technology has to be the next plan of the center and the livestock and fishery resources development agency. Furthermore, pre-scaling up the technology has to be planned and local manufacturers shall be trained to make the technology available near to the farmers. Moreover, this technology can be considered in plan of the government for unemployment reduction in the country.

\section{REFERENCES}

Ethiopian Statistical Authority (1985-1996): Livestock, poultry and beehives population. Agricultural sample survey. Ethiopian Central Statistics Authority, Addis Ababa, Ethiopia

Hoyle E (1992): Small scale poultry keeping in Welaita, North Omo region. Farmers Research Project. Technical Pamphlet No 3, Farm Africa, Addis Ababa, Ethiopia

Mekonnen G (2007): Characterization of the small holder poultry production and marketing system of dale, wonsho and loka abaya weredas of snnprs. MSc Thesis. Hawassa University.

Solomon (1999) Suitability of homemade hay-box chick brooder to the Ethiopian household poultry production system. Proceedings of the $7^{\text {th }}$ annual Conference of the Ethiopian Society of Animal Production. Addis Ababa, Ethiopia

Sub-Sector Review 4 (1984): The Ethiopian livestock sub-sector review. Volume 2 Annex 5. Addis Ababa, Ethiopia

Tadelle D, Ogle B (2001): Village Poultry Production System in the Central High Lands of Ethiopia. Tropical Animal Health and Production, of Animal, Wildlife and Grassland Sciences, 33: 521-537. 